\title{
Factors influencing social media usage among Farm youth in rural communities of Federal Capital Territory (FCT), Nigeria
}

\author{
Babasanya Bankole, Abdulkarim, S. B, Ganiyu, L., Danbaki, C. A., Okechalu, S. \\ 0., Akure, C. O., Lapkat, L. G., Adetunji, A. J., Bako, A., \& Jayeola, E. 0. \\ Federal college of Forestry Mechanization, Kaduna
}

Aderounmu, A. F., Federal college of Forestry, Ibadan

\begin{abstract}
The study assessed factors influencing social media usage for agricultural information dissemination among farm youth in rural communities of the Federal Capital Territory (FCT), Nigeria. Multi-stage sampling was used to select 212 respondents. Structured interview schedule was used to collect data, and analysed with descriptive statistics and factor analysis. The result from the study showed that majority (59.9\%) of the farm youth were between the ages of 15 and 24 years with mean age range of $23.8 \pm 2.76,68 \%$ had completed secondary school while $68 \%$ practiced Christianity. The study further identified socioeconomic and social media related as two factors that emerged from factor analysis of ten variables. The study recommended that the use of social media for agricultural information dissemination should consider users' education, values and culture as well as the availability and accessibility of the media and, the level of knowledge of social media the beneficiaries have for maximum benefit.
\end{abstract}

Keywords: Farm youth, factors, social media, usage, influence

\section{INTRODUCTION}

Despite the establishment of different agencies and backed with several extension approaches and strategies with the aim of boosting farmers' production, yet, agricultural performance remains unimpressive resulting in continued food importation and increase in consumer price index (CPI). One of the factors responsible for this is poor communication of agricultural research results; and the fact that agricultural production in Nigeria has remained in the hands of ageing and aged who are averse to modern information and communication technologies (Sokoya, 2012; FA0, 2014b). Therefore, there is urgent need to attract youth into agriculture for farm succession.

Youth's participation in agriculture in many developing countries presents an impressive but rather an unstable picture (Maïga et al., 2015 and McMillan and Hartgen, 2014), largely because the sector is perceived by youth as highly unattractive due to risks, costs, inefficiency and its labour intensive nature (Irungu et al., 2015). For instance Maïga et al. (2015) estimated participation rates in 
agricultural labour for the youth using data from six countries: Ethiopia, Malawi, Niger, Nigeria, Tanzania, and Uganda. Their findings showed that the youth (16-35 years of age bracket) has participation rates in agricultural labour that ranges from $27.1 \%$ in Nigeria to $63.4 \%$ in Niger. In northern Nigeria, the probability that youth are working in agriculture is higher $(36.5 \%)$ than that of the youth in southern Nigeria (17.8\%). McMillan and Hartgen (2014) estimated the probability of working in agriculture for people of 25 years and above using Demographic and Health Surveys (DHS) data from 24 African countries, including the six countries already mentioned. Their estimates are higher than Maïga et al. (2015) for Ethiopia (60.9\% versus $51.8 \%$ ), Tanzania (65.6\% versus $46.3 \%$ ) and Uganda (67.1\% versus $53.9 \%$ ). The reverse is true for Malawi (54.4\% versus $51.4 \%$ ), Niger (60.2\% versus $44.8 \%$ ) and Nigeria (33.8\% versus $32.0 \%$ ).

Thus, motivating the youth to view agriculture as a career opportunity requires a multi-level intervention. At the organizational level, a body known as Youth Agro Entrepreneur (YAE) in Abuja, Nigeria with continuous initiatives to support youth in agricultural enterprises and widen the opportunities to showcase their successes in order to attract more young people into agriculture especially through the use of mobile technology and social media has been formed. YAE is a social enterprise incubator that seeks to rebrand farming as a sustainable and profitable profession for the rural youth through the incorporation of one of the information and communication technologies (ICTs) such as the internet, mobile phones, computers and Global Positioning Systems (GPS) associated or not with traditional communication technologies such as radio, television, written press and video (YAE, 2012). YAE is particularly concerned with the usage of smart phone among the youth to boost rural agriculture in the FCT.

Youth is defined by ILO (2010a) as the age group 15 to 24 years and 'Farm youth' according to Torimiro (2013) 'is a child that has farmers' parentage; are raised and nurtured in the farm environment; socialized into farming from their childhood; relate with members of the farm family and the entire farm community; develop potentials in farming activities into which they are socialized; and grow to participate in the farming activities and develop their personality'.

\section{STATEMENT OF RESEARCH PROBLEM}

Social media refers to the internet-based digital tools for sharing and discussing information among people. It also refers to facts or knowledge needed to answer some questions faced by people in their daily life. People's needs for information varies from decision making through psychological to some more individual centered needs. According to Lwoga et al. ((2011), the need for information with regards to development is pertinent to a person's occupation, the level of socio-economic development, and local agro-ecological conditions. Information needs of the rural poor are specifically related to their occupations and their basic survival objectives. While physiological needs give rise to basic and often shared information needs, individual needs vary from one person to another. A number of interrelated factors including social, cultural and economic can influence individual information needs. Others include the information seeker's age, level of education, gender, and income can also influence information needs. Lwoga et al. (2010) further asserts that information and other needs of rural people are distinctive due to varied demographic, social, cultural and economic factors. Invariably, these factors can influence how social media is used in virtual communities. 
Bankole, B., Abdulkarim, S. B, Ganiyu, L., Aderounmu, A. F., Danbaki, C. A., Okechalu, S. O., Akure, C. O., Lapkat, L. G., Adetunji, A. J., Bako, A., \& Jayeola, E. O. (2020) Knowledge Factors influencing social media usage among Farm youth in rural communities of Federal Capital Territory (FCT), Nigeria. Advances in Social Sciences Research Journal, 7(4) 454-461.

According to Agwu, Uche-Mba and Akinnagbe (2008) there is likely to be stagnation in the dissemination, utilization and application of scientific agricultural information for purposeful development of the system if modern ICT facilities (such as social media) are not adequately built into the mainstream of Nigerian agricultural extension system. This study therefore sought to determine factors influencing social media usage among farm youth in rural communities of Federal capital territory, Nigeria. The specific objectives are to;

1. Identify the factors influencing social media usage;

2. Describe some demographic characteristics of respondents in the study area;

\section{METHODOLOGY}

The study was conducted in the Federal Capital Territory (FCT), Abuja Nigeria, which was created in 1976, while the city was built throughout the 1980s. It officially became Nigeria's capital on December 12, 1991, replacing the role of the previous capital, Lagos. The Federal capital Territory is located between latitudes $8^{0} 25^{\mathrm{I}}$ and $9^{0} 25^{\mathrm{I}}$ North of the equator and longitudes $6^{0} 45^{\mathrm{I}}$ and $7^{\mathrm{O}} 45^{\mathrm{I}}$ east of Greenwich Meridian. The territory covers an area of 8,000 square kilometers and occupies about $0.87 \%$ of Nigeria. The Federal Capital Territory is divided into three Crop ecological zones, namely: the southern humid zones, mid-central sub humid zones and north east humid zones. Data used for this study was collected from farm youth who have used one type of social media or the other to carry out farming activities in three out of six area councils selected. The area councils are Bwari, Gwagwalada and Kuje. Six rural communities were selected from each of the selected area councils, making a total of 18 rural communities. Lastly, 13 respondents were chosen from each of the selected rural communities through snowball sampling technique to make a total of 234 respondents. But the 212 retrieved questionnaires were used for the study. The questionnaire were administered by the investigator and some facilitators. The socioeconomic characteristics and factors influencing social media usage were measured by Yes or No in which Yes $=1$, and No $=0$ respectively. Data were analysed using frequency count and percentages and Factor analysis.

\section{Factors influencing social media usage}

\section{RESULT AND DISCUSSION}

For ease of identification of important factors that influenced social media use among farm youth in Federal Capital Territory, data were subjected to Factor analysis using Principal Component Analysis and orthogonal Varimax rotation. All Kaiser-Meyer-Olkin (KMO) coefficient for the individual items was 0.872 which were well above 0.5 implying that the data were sufficient for exploratory factor analysis (EFA). The Bartlett's test of sphericity (BTS) $\chi 2(45)=600.91$ showed that there were patterned relationship between the items. Considering the eigen value cut-off of 1.0, there were three factors that explain a cumulative variance of $41.21 \%$. The scree plot confirmed the findings of retaining two factors. The Table 1 that follows shows the factor loading after rotation using a significant factor criterion of 3 . For clear understanding of factor analysis, the interpretation is based on three parameters: rotated factor loading, rotated eigen value and scree plot (Figure 1) in line with Yong and Pearce (2013). 
Table 1: Extraction Method: Principal Axis Factoring for the Factors Influencing Social Media Usage

\begin{tabular}{|c|c|c|c|c|c|c|c|c|c|}
\hline \multirow{2}{*}{ Factor } & \multicolumn{3}{|c|}{ Initial Eigenvalues } & \multicolumn{3}{|c|}{$\begin{array}{l}\text { Extraction Sums of Squared } \\
\text { Loadings }\end{array}$} & \multicolumn{3}{|c|}{$\begin{array}{c}\text { Rotation Sums of Squared } \\
\text { Loadings }\end{array}$} \\
\hline & Total & $\begin{array}{c}\% \text { of } \\
\text { Variance }\end{array}$ & $\begin{array}{l}\text { Cumulati } \\
\text { ve } \%\end{array}$ & Total & $\begin{array}{c}\% \text { of } \\
\text { Variance }\end{array}$ & $\begin{array}{l}\text { Cumulati } \\
\text { ve } \%\end{array}$ & Total & $\begin{array}{c}\% \text { of } \\
\text { Variance }\end{array}$ & $\begin{array}{l}\text { Cumulati } \\
\text { ve } \%\end{array}$ \\
\hline 1. Age & 3.925 & 39.254 & 39.254 & 3.463 & 34.625 & 34.625 & 2.609 & 26.094 & 26.094 \\
\hline 2. Education & 1.062 & 10.615 & 49.869 & .383 & 3.829 & 38.454 & 1.074 & 10.739 & 36.833 \\
\hline 3. Income & 1.016 & 10.155 & 60.025 & .276 & 2.758 & 41.213 & .438 & 4.380 & 41.213 \\
\hline 4. Culture & .904 & 9.042 & 69.066 & & & & & & \\
\hline 5. Value orientation & .715 & 7.151 & 76.217 & & & & & & \\
\hline 6.Keyboard-shy & .647 & 6.473 & 82.690 & & & & & & \\
\hline 7. Availability & .607 & 6.074 & 88.764 & & & & & & \\
\hline 8. Accessibility & .475 & 4.754 & 93.518 & & & & & & \\
\hline 9. Knowledge & .356 & 3.557 & 97.075 & & & & & & \\
\hline 10. Time wasting & .292 & 2.925 & 100.000 & & & & & & \\
\hline
\end{tabular}

Source: Field Survey, 2017.

Principal Component Analysis of factors influencing social media usage among Farm youth

Table 2 showed the actual factors that were extracted or isolated and their respective variable contributions to social media usage. From the table under 'rotated sum of squared loadings' it revealed that there are three factors with eigen values greater than one (1). Also, '\% of variance' column reveals how much of the variability can be accounted for by each of the factors. Thus, Factor 1 accounts for 26.094 percent of the variability in all the ten variables. Factor 2 accounts for 36.833 percent of the variability in all the ten variables and Factor 3 accounts for 41.213 percent of the variability in all the ten variables.

\section{Varimax with Kaiser Normalisation (Rotated Component Matrix).}

Table 3 depicted the Varimax rotated factors that influenced social media usage. The table reveals eight variables that loaded strongly on factor1.Three of them including education, compatibility with culture and value orientation strongly loaded on factor 1 and was tagged them 'Sociocultural, factor. However, availability and knowledge which concurrently loaded on factors 1 and 2 were regarded as complex variables and discarded in accordance with Yong and Pearce (2013).

Also, availability, knowledge and (accessibility loaded fairly strongly) on factor 2 which was tagged 'Social media-related' factor. While Age loaded strongly on factor 3 and was tagged it 'Socioeconomic' factor but since it did not load strongly on either of sociocultural and social media factors, the two factors have emerged strongly resulting to larger factor loadings (Table 24). The implication of this finding is that sociocultural and social media-related factors are the two main factors influencing social media usage among the farm youth in the study area, and it is similar to Lwoga et al. (2013) that socio cultural factors influenced the choice of an information source used among small scale farmers in Tanzania. However, it is contrary to Yekinni and Ladele (2014) who found socioeconomic as the main determinant of ICT use among farmers in Oyo state. 
Bankole, B., Abdulkarim, S. B, Ganiyu, L., Aderounmu, A. F., Danbaki, C. A., Okechalu, S. O., Akure, C. O., Lapkat, L. G., Adetunji, A. J., Bako, A., \& Jayeola, E. O. (2020) Knowledge Factors influencing social media usage among Farm youth in rural communities of Federal Capital Territory (FCT), Nigeria. Advances in Social Sciences Research Journal, 7(4) 454-461.

Table 4: Factor analysis showing factors that influenced social media usage among farm youth in the study area.

\begin{tabular}{|c|c|c|c|}
\hline Variable & Sociocultural & Social media-related & Socioeconomic \\
\hline Age & & & 0.528 \\
\hline Education & 0.718 & 0.195 & 0.270 \\
\hline Income & 0.475 & 0.272 & \\
\hline Culture of people & 0.571 & & 0.174 \\
\hline Value orientation & 0.554 & 0.194 & 0.148 \\
\hline Keyboard shy & 0.410 & & 0.148 \\
\hline Availability & 0.410 & 0.625 & \\
\hline Accessibility & 0.723 & 0.457 & \\
\hline Knowledge & 0.554 & 0.537 & $\mathbf{0 . 4 3 8}$ \\
\hline Time wasting & & 0.126 & $\mathbf{4 . 3 8 0}$ \\
\hline Eigen value (L ${ }^{2}$ ) & $\mathbf{2 . 6 0 9}$ & $\mathbf{1 . 0 7 4}$ & $\mathbf{4 1 . 2 1 3}$ \\
\hline \% variance & $\mathbf{2 6 . 0 9 4}$ & $\mathbf{1 0 . 7 3 9}$ & \\
\hline Cumulative \% & $\mathbf{2 6 . 0 9 4}$ & $\mathbf{3 6 . 8 3 3}$ & \\
\hline
\end{tabular}

Source: Field Survey, 2017

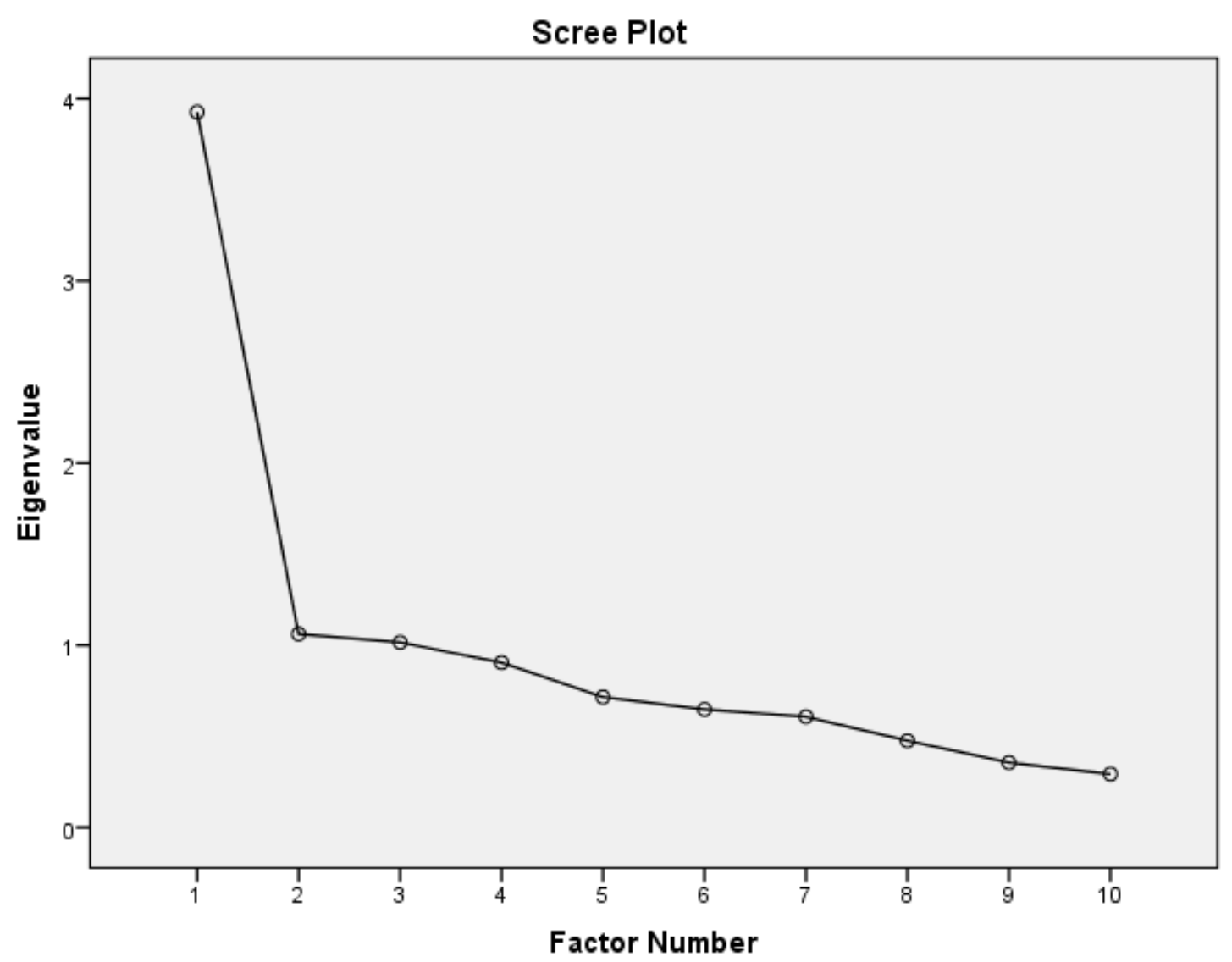


After the merging of socio cultural and social media-related factors and the removal of socioeconomic factor and other variables which did not strongly loaded to either of the two main factors, only two factors evolved as shown in table 5 below.

\section{Factor 1: Socio-cultural}

Results in Table 5 showed that there are three strongly loaded variables which contribute significantly to socio-cultural factors. These are Education $(\mathrm{L}=0.718)$, Culture of the people $(\mathrm{L}=$ 0.571 ) and Value orientation ( $\mathrm{L}=0.554)$. Education is required to know how to use social media since it is technology oriented. Also, any innovation or idea that contradicts the culture of the people will be rejected. Similarly, where an idea is not seen to be of benefit or bring improvement to the people's status, it may likely not be accepted. Therefore, these factors had influence on the use of social media among the farm youth in the study.

\section{Factor 2: Social media-related}

Table 5 revealed the three variables that loaded strongly and contributed to social media-related factor. These are availability $(\mathrm{L}=0.625)$, knowledge $(\mathrm{L}=0.537)$ and accessibility $(\mathrm{L}=0.457)$. These influenced social media usage in that availability of the media will provide it for people's consumption while accessibility will help the users to get it. It indicates how easy or otherwise it can be reached and used. Also, knowledge is required to ascertain the understanding of the user about the media. This implies that availability, accessibility and knowledge greatly influenced social media usage.

In conclusion, any programme that will encourage the use of social media for agricultural information dissemination would consider education of the users, have respect for their values and culture while it ensures the availability and accessibility of the media as well as ascertain the level of knowledge the beneficiaries have about it.

Table 5: Analysis showing the merging of variables that contributed to the emergence of two factors that influenced social media usage among farm youth

\begin{tabular}{|c|c|c|c|}
\hline Factors (Variables) & $\mathbf{L}$ & $\mathbf{L}^{\mathbf{2}}$ & $\mathbf{X L}^{\mathbf{2}}=\mathbf{X}$ \\
\hline \multicolumn{5}{|c|}{ Factor 1 (Socio-cultural) } \\
\hline Education & 0.718 & 0.515 & 1.148 \\
\hline Culture of the people & 0.571 & 0.326 & \\
\hline Value orientation & 0.554 & 0.307 & 0.887 \\
\hline \multicolumn{5}{|c|}{ Factor 2 (social media-related) } \\
\hline Availability & 0.625 & 0.390 & \\
\hline Knowledge & 0.537 & 0.288 & \\
\hline Accessibility & 0.457 & 0.209 & \\
\hline
\end{tabular}

Source: Field Survey, 2017.

$\mathrm{L}=$ loading for factors, $\mathrm{L}^{2}=$ square of factor loading, $\mathrm{X}=$ latent root for the factor 
Bankole, B., Abdulkarim, S. B, Ganiyu, L., Aderounmu, A. F., Danbaki, C. A., Okechalu, S. O., Akure, C. O., Lapkat, L. G., Adetunji, A. J., Bako, A., \& Jayeola, E. O. (2020) Knowledge Factors influencing social media usage among Farm youth in rural communities of Federal Capital Territory (FCT), Nigeria. Advances in Social Sciences Research Journal, 7(4) 454-461.

\section{Demographic Characteristics of Respondents}

\section{Age}

The results showed the age of farm youth in the study area. Majority (59.9\%) of the farm youth were between the ages of 15 and 24 years, 37 percent between 25 and 34 years while very few (2.8\%) were above 35 years. Mean age of farm youth was 23.8 years with a standard deviation of 2.76. This result affirmed that age group 15-24 years is youth category as reported by International Labour Organisation (ILO) (2010a) definition of youth.

\section{Sex}

The results showed that majority (63.7\%) of the farm youth were males, while remaining (36.3\%) were females. This study implies that males were more involved in social media usage than females. This result is similar to Banmeke and Oose (2012) who reported that most (61.4\%) of the researchers who use social network sites (SNTs) were male while 38.6 percent were females. This implies that male use social media than females for agricultural information dissemination.

\section{Educational level}

The results revealed that majority (63\%) of the respondents had secondary education, 28.9 percent had primary education while only 8.1 percent had tertiary level of education. This is similar to Tyabo (2015) who reported that 8.1 percent had tertiary education among male phone users in rural areas of Niger State. This implies that majority (91.9\%) of the respondents have a low level of education in the study area.

\section{Religion}

The results indicated that majority (65.9\%) were Christians, 36.3 percent were Muslims and only 1.4 percent were traditional worshippers. These results indicated that the respondents were mainly Christians and Muslims, and could be identified through faith based organizations in case of livelihood intervention programmes such as social media usage.

\section{CONCLUSION AND RECOMMENDATION}

From the study, the mean age of respondents was $23.8 \pm 2.76$. Majority $(67.3 \%)$ of the respondents were male, while $13.5 \%$ were female Majority (65.9\%) of the respondents practiced Christianity, (32.7\%) practiced Islam while (1.4\%) were traditional worshippers. About (28.9\%) of the respondents completed primary school, (68.0\%) completed secondary while (8.1\%) had tertiary education. The study further identified 'sociocultural and social media-related' as the two factors which influenced social media usage for agricultural information dissemination among farm youth. These factors comprised of six variables namely education, culture, value orientation, availability, knowledge and accessibility.

The study recommended that any programme that will encourage the use of social media for agricultural information dissemination would consider education of the users, have respect for their values and culture while it ensures the availability and accessibility of the media as well as ascertain the level of knowledge the beneficiaries have about it for maximum benefit. 


\section{References}

Food and Agriculture Organisation of the United Nations. (2014b): Youth and agriculture: Key challenges and concrete solutions. Rome, Italy: FAO in collaboration with the Technical Centre for Agricultural and Rural Cooperation and the International Fund for Agricultural Development.

Irungu, K. R. G., Mbugua, D. and Muia, J. (2015) Information and Communication Technologies (ICTs) Attract Youth into Profitable Agriculture in Kenya, East African Agricultural and Forestry Journal, 81:1, 24-33.

Maiga, E., Christiaensen, L. and Palacios-Lopez, A. (2015). “Are the Youth Exiting Agriculture en Mass?” Mimeo.

McMillan, M. and Harttgen, K. (2014): The changing structure of Africa's economies. National Bureau of Economic Research working Paper 20077. Cambridge, MA: NBER. Retrieved from http://legacy.wlu.ca/documents/57803/McMillian_ChangingAfrica_140317.pdf.

Torimiro, D.O. (2013): “Who will bring farm children back to farm?” Inaugural Lecture Series 257. Obafemi Awolowo University, Ile Ife, P 8, 18-22, 34, 36.

YAE (2012): Young Agro- Entrepreneur, "Smart phones and rural farming in Nigeria".

ILO. (2010a): International Labour Organization global employment trends 2014: Risk of a jobless recovery? ILO, Geneva.

Lwoga. E. (2010): "Application of Knowledge Management Approaches and Information and Communication Technologies to Manage Indigenous Knowledge in the Agricultural Sector in Selected Districts of Tanzania." The Electronic Journal of Information Systems in Developing Countries (EJISDC) 25.

Lucas, K. and Sherry, J. (2004): "Sex Differences in Video Game Play: A Communication-Based Explanation”. Communication Research, 31, 499-523.

Lwoga, E. T., P. Ngulube and C. Stilwell (2011): "Information Needs and Information Seeking Behaviour of Small-Scale Farmers in Tanzania." Innovation: Journal of Appropriate Librarianship and Information Work in Southern Africa 40 (2010). Sabinet

Yong A.G and Pearce, S (2013): A Beginner's Guide to Factor analysis : focusing on exploratory factor analysis. Tutorials on Quantitative Methods for Psychology Vol. 9 (2).

Yekinni, O. T. and Akinbile, L. A. (2014): Comparative Assessment of Use of Information and Communication Technologies by Agricultural Researchers and Extensionists in Southwestern Nigeria. Presented at the 19th annual conference of the Agricultural Extension Society of Nigeria held at Federal University of Technology, Owerri, Nigeria between 27 and 30 April

Tyabo, I.S., Adesiji, G.B., Ibrahim, M, I.S. Umar and Ndanisa, M.A. (2015): Perceived effects of mobile phone on the livelihood of Rural dwellers in Niger state, Nigeria. Proceedings 20 $0^{\text {th }}$ Annual National Conference of the Agricultural Extension Society of Nigeria (AESON) held at NAERLS, ABU, Zaria.

Banmeke, T.O.A and Oose, M. O. (2012): Assessment of the Use of Social Network Tools (SNTs) by Agriculture Researchers in South West Nigeria, Journal of Communications of the IIMA Volume 12 Issue 